\title{
Progesterone concentration in the marsupial Sminthopsis macroura: relationship with the conceptus, uterine glandular regeneration and body weight
}

\author{
E M Menkhorst, L A Hinds ${ }^{1}$ and L Selwood \\ Department of Zoology, The University of Melbourne, Melbourne, Victoria, 3010 Australia and ${ }^{1}$ CSIRO Entomology, \\ Canberra, Australian Capital Territory, 2601 Australia \\ Correspondence should be addressed to L Selwood; Email: I.selwood@zoology.unimelb.edu.au \\ E M Menkhorst is now at Prince Henry's Institute of Medical Research, Clayton, Melbourne, Victoria, 3168 Australia
}

\begin{abstract}
Close examination of hormonal profiles and uterine morphology in the marsupial reproductive cycle highlights significant differences between pregnant and non-pregnant cycles. In the polyovular dasyurid marsupial Sminthopsis macroura, we identified changes associated with gestation by comparing ovarian and plasma progesterone concentrations, uterine weights, uterine epithelial mitoses, body weights and gestation lengths between pregnant and non-pregnant luteal phases. The plasma progesterone profile of $S$. macroura was biphasic, peaking during unilaminar blastocyst expansion and on the day of implantation. Periods of rapid embryonic development were associated with increasing plasma progesterone concentrations and animal body weight. For the first time in a polyovular marsupial, we identified 1) a correlation between ovarian progesterone concentration and conceptus number during the luteal phase just prior to implantation (total ovarian progesterone), indicating a conceptus influence on progesterone concentration; 2) a pulse of uterine epithelial mitotic activity at the time of implantation and 3) increased mitotic activity in pregnant animals during unilaminar blastocyst formation compared with non-pregnant animals. Gestation length was reduced by up to $15 \%$, due to the loss of, or reduction in, the fourcell arrest and more rapid definitive blastocyst expansion. This is the first time a conceptus influence on gestation length has been identified in a dasyurid. This study provides further evidence for the modification of the luteal phase by pregnancy in $S$. macroura. Reproduction (2009) 137 107-117
\end{abstract}

\section{Introduction}

The similarity between pregnant and non-pregnant reproductive cycles in marsupials has often been emphasized (Tyndale-Biscoe \& Renfree 1987). However, pregnancy-specific hormonal and morphological changes are found during gestation in both monovular (Von der Borch 1963, Renfree 1972, 1973, Renfree \& Tyndale-Biscoe 1973, Cake et al. 1980, Hinds \& Tyndale-Biscoe 1982, Curlewis \& Stone 1986) and polyovular (Fleming \& Harder 1981, Fletcher 1989, Hinds 1989, Cruz \& Selwood 1993, 1997) marsupial species.

In both pregnant and non-pregnant marsupial cycles, low pre-ovular plasma progesterone concentrations rise steadily to a peak late in gestation, before falling to low levels at birth. A transient progesterone peak during unilaminar blastocyst formation occurs in some species and is higher in the pregnant than the non-pregnant macropodids Setonix brachyurus (significantly) (Cake et al. 1980) and Macropus eugenii (Hinds \& TyndaleBiscoe 1982), and the dasyurids Dasyurus viverrinus (Hinds 1989) and Antechinus agilis (Hinds \& Selwood
1990; previously Antechinus stuartii (Dickman et al. 1998)), according to the developmental timetables given in Cake et al. (1980), Selwood (1980) and Tyndale-Biscoe \& Renfree (1987) respectively. The decline in progesterone just prior to birth occurs earlier and more rapidly in pregnant S. brachyurus (Cake et al. 1980), M. eugenii (Hinds \& Tyndale-Biscoe 1982, Tyndale-Biscoe et al. 1983), Dasyuroides byrnei (Fletcher 1989) and D. viverrinus (Hinds 1989) than in non-pregnant cycles, but is more rapid in non-pregnant Trichosurus vulpecula (Curlewis et al. 1985).

Uterine development also differs between pregnant and non-pregnant cycles. In monovular macropods (Renfree 1972, Renfree \& Tyndale-Biscoe 1973) and $T$. vulpecula (Von der Borch 1963, Curlewis \& Stone 1986), the uterus ipsilateral to the corpus luteum (CL) is heavier, an effect that is enhanced by the conceptus during the second half of pregnancy in macropods (Renfree 1972, Renfree \& Tyndale-Biscoe 1973). The composition of secreted proteins differs between the two uteri in M. eugenii (Renfree 1973), and in T. vulpecula the mitotic rate of the ipsilateral glandular epithelium is significantly 
higher on day 2 post-oestrus (Von der Borch 1963), equivalent to day 1 post-ovulation (Shorey \& Hughes $1973 b$ ). In the polyovular dasyurids $A$. agilis (Cruz \& Selwood 1993) and Sminthopsis macroura (Cruz \& Selwood 1997), the endometrial stroma, luminal and glandular epithelium are significantly thicker in pregnant cycles compared with non-pregnant cycles at specific stages of the luteal phase, but in the polyovular didelphid Didelphis virginiana, the non-pregnant uterine endometrium is significantly thicker on day 11 (Fleming \& Harder 1981), the day of implantation (Hartman 1928).

S. macroura, the stripe-faced dunnart, is a small dasyurid carnivore weighing 20-25 g (Woolley 1990). Its 10.7-day gestation is the shortest of any mammal (Selwood \& Woolley 1991), and it is both polyoestrous and polyovular (Woolley 1990).

Dasyurid daily body weight profiles are reliable indicators of oestrous cycles (Woolley 1966, 1990), possibly reflecting uterine mitosis and/or oedema (Tyndale-Biscoe \& Renfree 1987), and body weight is correlated with progesterone concentration in $D$. byrnei (Fletcher 1989). In S. macroura, the daily monitoring of body weight and vaginal cells in urine samples allows the reliable determination of both pregnant and nonpregnant cycles (Selwood \& Woolley 1991). Within $8 \mathrm{~h}$ of ovulation, fertilized eggs enter the uterus (Selwood \& Woolley 1991, Menkhorst et al. 2007), and the first cleavage is complete within $24 \mathrm{~h}$ (Selwood \& Hickford 1999). A period of four-cell stage arrest occurs on day 1.5 and cleavage resumes by day 2.5. The unilaminar blastocyst is formed on day 3 and a period of slow development occurs until day 6.5 when the rapid formation of the bilaminar blastocyst occurs. Subsequent development is extremely rapid, with the primitive streak visible on day 8.0, and birth occurring within 2.5 days (Selwood \& Hickford 1999).

Here, we present the first ovarian and plasma progesterone profiles for $S$. macroura. We correlated progesterone concentration with both corpora lutea $(\mathrm{CL})$ and conceptus number to identify any conceptus influence on progesterone concentration. We also correlated progesterone concentration with uterine and animal body weight, and developed the first uterine epithelial daily mitotic index in a marsupial to investigate the pattern of uterine glandular epithelial regeneration.

\section{Results}

Average conceptus number (Fig. 1) throughout gestation was $15.3(+0.9, n=91)$. Daily average conceptus number fell significantly during gestation (Fig. 1) with significantly fewer conceptuses found after day 6 than those found on day $1(P<0.001)$. The largest loss of conceptuses occurred from days 8 to 9 (10.8-5.3 conceptuses per animal; Fig. 1), as previously identified by Selwood \& Woolley (1991).

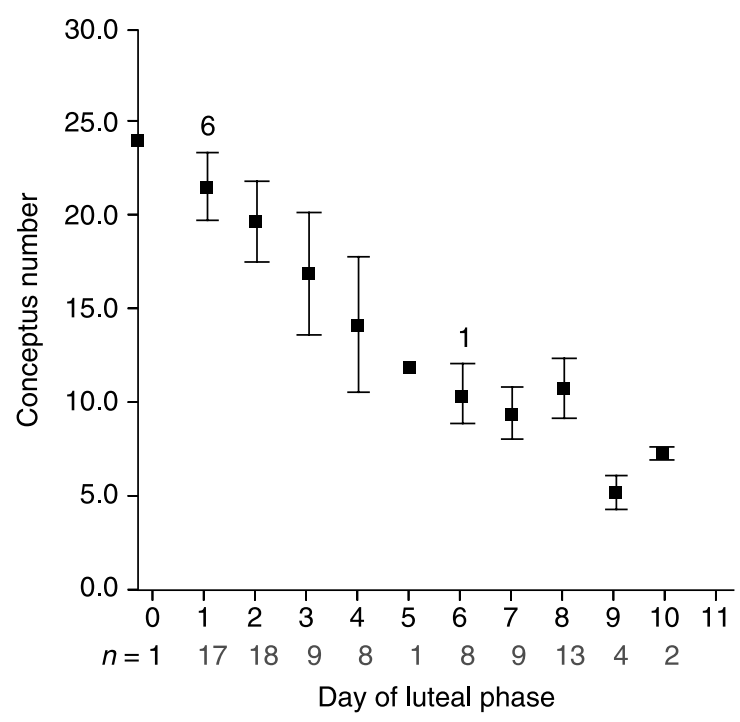

Figure 1 Average daily conceptus number throughout gestation (luteal phase) in pregnant $S$. macroura. Conceptus number fell throughout gestation, with significantly fewer conceptuses found on and after day 6 than on day 1 of gestation $\left(F_{8,80}=5.294, P<0.001\right)$.

\section{Ovarian progesterone}

Ovarian progesterone concentration (ng/ovary, Fig. 2A; Table 1) was low at ovulation (day 0: 0.59 ng/ovary; $n=2)$, but increased significantly in pregnant animals (Fig. 2A; $P<0.001)$ from day 1 (2.8 ng/ovary; $n=5)$, during early cleavage, to peak on day 4 (43.6 ng/ovary; $n=4)$, the day of unilaminar blastocyst expansion.

\section{Plasma progesterone}

Plasma progesterone concentration (ng/ml, Fig. 2B; Table 1) was low during the follicular phase. After ovulation, progesterone increased significantly (Fig. 2B; $P<0.001)$ from day $1(1.87 \mathrm{ng} / \mathrm{ml}, n=16)$ to peak on days $4(14.63 \mathrm{ng} / \mathrm{ml}, n=6)$ and $9(17.43 \mathrm{ng} / \mathrm{ml}, n=4)$, the day of implantation.

\section{Variation in progesterone concentration}

\section{$C L$ number and progesterone concentration}

A regression analysis using all pregnant individuals sampled throughout the luteal phase showed a significant correlation between $\mathrm{CL}$ number and ovarian progesterone concentration (Fig. 3A; $P=0.004$ ). The number of $\mathrm{CL}$ present showed the most influence on ovarian progesterone concentration between day 3 , the day when the $\mathrm{CL}$ have completed cell division and hypertrophy of luteal cells is initiated (Selwood \& Woolley 1991), and day 7 (controlling for conceptus number; $r=0.5892, n 25, P<0.001)$, the day of bilaminar blastocyst formation and when the luteal cells reach their greatest size (Selwood \& Woolley 1991). Day 7 was the only day to show an individual correlation 


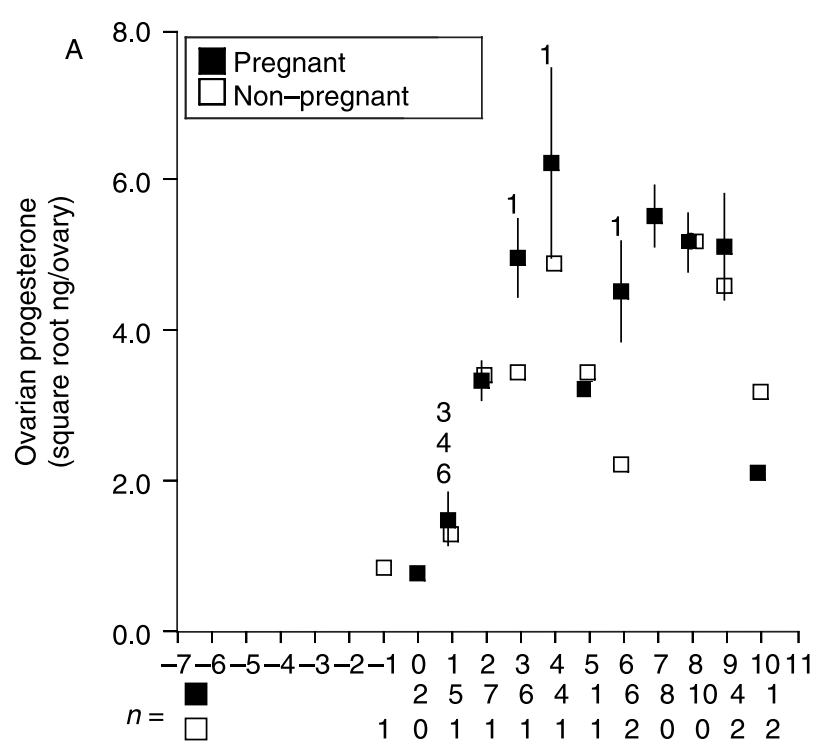

Day of follicular and luteal phase

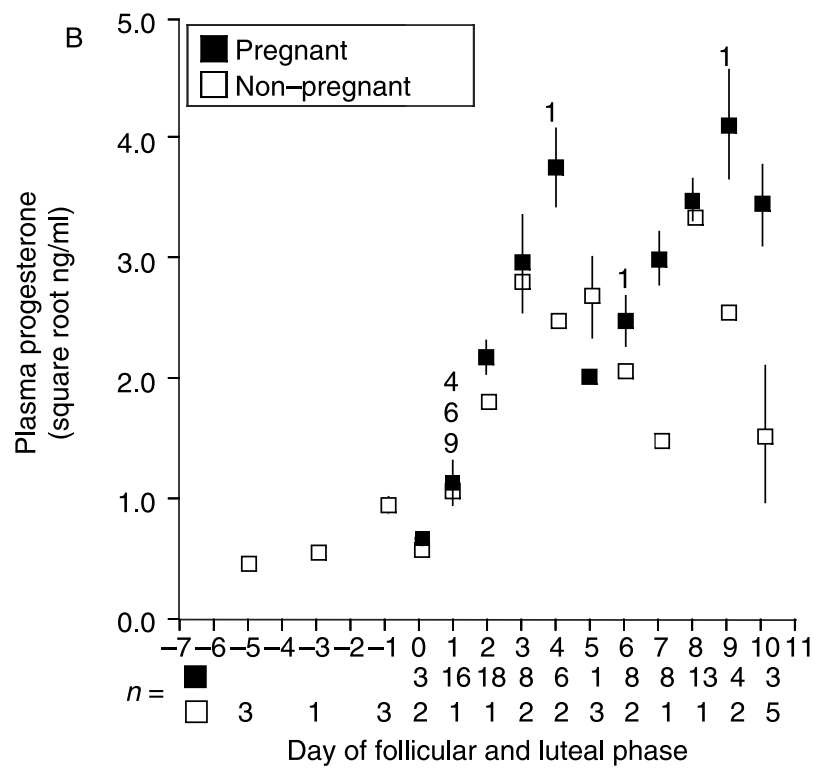

Figure 2 Progesterone concentration in (A) ovarian tissue and (B) plasma during the follicular and pregnant or non-pregnant luteal phase in $S$. macroura. Oestrus occurs between days -3 and -1 , ovulation occurs at time 0 and birth occurs on day 11 (Selwood \& Woolley 1991). (A) Ovarian progesterone increased significantly from day 1 to peak in early gestation on day 4 of the luteal phase $\left(F_{10,43}=5.838, P<0.001\right)$. (B) Plasma progesterone increased significantly from day 1 to peak on days 4 and 9 of the luteal phase $\left(F_{9,77}=14.339, P<0.001\right)$. Significant changes in progesterone concentration between the days of the pregnant luteal phase are indicated by the numbers above the daily concentration. $n$, sample size.

between $\mathrm{CL}$ number and total ovarian progesterone concentration (Fig. 3A; $P=0.050$ ), with $57 \%$ of all variance in total ovarian progesterone explained by $\mathrm{CL}$ number. This correlation was no longer found on day 8 (controlling for conceptus number; $r=-0.0645, n=6$, $P=0.879$ ), the day before the day of implantation.
A regression analysis using all pregnant individuals sampled throughout the luteal phase showed a significant correlation between $\mathrm{CL}$ number and plasma progesterone concentration (Fig. 3B; $P=0.015$ ). Most $\mathrm{CL}$ influence (Fig. 3B) was observed between days 3 and 9 (controlling for conceptus number; $r=0.3341, n=53$ $P=0.013)$. Day 3 was the only individual day to show a correlation between $\mathrm{CL}$ number and plasma progesterone concentration (Fig. 3B; $P=0.030$ ), with $57 \%$ of all variance explained by $\mathrm{CL}$ number. This correlation was no longer found on day 4 (controlling for conceptus number; $r=0.0347, n=5, P=0.941$ ).

\section{Conceptus number and progesterone concentration}

Conceptus number was significantly correlated with ovarian progesterone on day 8 (Fig. 3C; $P=0.048$ ) when no $\mathrm{CL}$ influence was found (Fig. $3 \mathrm{~A}$ ). Conceptus number was correlated with plasma progesterone concentration, but this was non-significant when $\mathrm{CL}$ number was included as a possible influence (Fig. 3D). The raw data for ovarian progesterone concentration and $\mathrm{CL}$ number (Fig. 3E) or conceptus number (Fig. 3F) on day 8 of the luteal phase are shown in Fig. $3 \mathrm{E}$ and $\mathrm{F}$.

\section{Uterine weight}

Uterine weight (\% daily body weight) increased significantly after ovulation between days 1 and 2, 2 and 3, 3 and 4 , and 7 and 8 in pregnant animals (Fig. 4; $P<0.001$ ), peaking at $9.9 \pm 1.9 \%$ of body weight on day 8 (Fig. 4). Power testing showed that a minimum of three samples was required to show a significant difference between pregnant and non-pregnant animals on each day of the luteal phase, so no statistical tests were carried out to compare uterine weight between pregnant and non-pregnant samples.

Uterine weight was strongly positively correlated with plasma progesterone concentration in both non-pregnant $(r=0.709, n=21, P<0.001)$ and pregnant $(r=0.680, n 53, P<0.001)$ cycles.

\section{Changes in animal body weight and gestation lengths}

Daily animal body weight was positively correlated with uterine weight $(r=0.288, n=172, P<0.001)$, ovarian progesterone concentration $(r=0.409, n=63, P<0.001$ ) and plasma progesterone concentration $(r=0.389$, $n=81, P<0.001)$.

The average overnight change in body weight (\%) during the luteal phase was $3.2 \pm 2.6 \%(n=109)$; however, changes of up to $14 \%$ were observed. Average body weight peaked at $9.7 \pm 7.1 \%(n=109)$ above ovulation weight on day 8 .

Gestation length (10.8 days $\pm 0.9, n=109$ ) was no different to previous studies (Selwood \& Woolley 1991, Selwood \& Hickford 1999), with birth usually occurring on day 11 (51.4\%). However, birth was not uncommon 
Table 1 Ovarian and plasma progesterone concentration found on each day of the luteal phase in non-pregnant and pregnant $S$. macroura

\begin{tabular}{|c|c|c|c|c|c|c|c|c|}
\hline \multirow{3}{*}{$\begin{array}{l}\text { Day of luteal } \\
\text { phase }\end{array}$} & \multicolumn{4}{|c|}{ Ovarian progesterone (sq root) } & \multicolumn{4}{|c|}{ Plasma progesterone (sq root) } \\
\hline & \multicolumn{2}{|c|}{ Non-pregnant } & \multicolumn{2}{|c|}{ Pregnant } & \multicolumn{2}{|c|}{ Non-pregnant } & \multicolumn{2}{|c|}{ Pregnant } \\
\hline & Mean士s.E.M. & $n$ & Mean \pm S.E.M. & $n$ & Mean \pm s.E.M. & $n$ & Mean士s.E.M. & $n$ \\
\hline \multicolumn{9}{|l|}{-7} \\
\hline \multicolumn{9}{|l|}{-6} \\
\hline-5 & & & & & $0.44 \pm 0.06$ & 3 & & \\
\hline \multicolumn{9}{|l|}{-4} \\
\hline-3 & & & & & 0.56 & 1 & & \\
\hline \multicolumn{9}{|l|}{-2} \\
\hline-1 & 0.85 & 1 & & & $0.95 \pm 0.16$ & 3 & & \\
\hline 0 & & - & $0.77 \pm 0.07$ & 2 & $0.57 \pm 0.1$ & 2 & $0.65 \pm 0.09$ & 3 \\
\hline 1 & 1.30 & 1 & $1.48 \pm 0.84$ & 5 & 1.04 & 1 & $1.13 \pm 0.80$ & 16 \\
\hline 2 & 3.40 & 1 & $3.32 \pm 0.80$ & 7 & 1.79 & 1 & $2.17 \pm 0.69$ & 18 \\
\hline 3 & 3.43 & 1 & $4.94 \pm 1.37$ & 6 & $2.79 \pm 0.44$ & 2 & $2.95 \pm 1.22$ & 8 \\
\hline 4 & 4.87 & 1 & $6.21 \pm 2.58$ & 4 & $2.47 \pm 1.49$ & 2 & $3.75 \pm 0.86$ & 6 \\
\hline 5 & 3.45 & 1 & 3.20 & 1 & $2.67 \pm 0.62$ & 3 & 2.01 & 1 \\
\hline 6 & $2.20 \pm 1.73$ & 2 & $4.51 \pm 1.74$ & 6 & $2.04 \pm 0.86$ & 2 & $2.47 \pm 0.64$ & 8 \\
\hline 7 & & - & $5.50 \pm 1.27$ & 8 & 1.46 & 1 & $2.98 \pm 0.69$ & 8 \\
\hline 8 & & - & $5.50 \pm 1.40$ & 10 & 3.32 & 1 & $3.55 \pm 0.70$ & 12 \\
\hline 9 & $4.57 \pm 1.98$ & 2 & $5.10 \pm 1.47$ & 4 & $2.53 \pm 0.58$ & 2 & $4.10 \pm 0.94$ & 4 \\
\hline 10 & $3.18 \pm 2.67$ & 2 & 2.11 & 1 & $1.53 \pm 1.33$ & 5 & 0.69 & 1 \\
\hline
\end{tabular}

on day $10(28.4 \%)$, and gestation lengths of $9(7.3 \%), 12$ $(10.1 \%)$ and $13(2.8 \%)$ days were also observed.

Gestation length was negatively correlated with litter size $(r=-0.294, n=109, P=0.002)$, with longer gestation lengths found when fewer young were born. This correlation became stronger when we controlled for the month of the year that the luteal phase occurred $(r=-0.3413, \mathrm{df}=106, P<0.001)$. Average gestation length shortened during the later months of the breeding season (August: $10.9 \pm 0.2$ days, $n=13$; September: $10.7 \pm 0.1$ days, $n=43$; October: $10.8 \pm$ 0.2 days, $n=18$; November $10.6 \pm 0.2$ days, $n=18$; December $10.3 \pm 0.5$ days, $n=6$ ), but there was no significant correlation between gestation length and month $(r=-0.120, n=109, P=0.214)$. Thus, a reduced gestation length was associated mainly with larger litters.

A clear pattern of daily body weight change was found for each gestation length and the pattern for a normal (11-day; $n=56)$ and shortened (9-day; $n=8$ ) gestation are shown in Fig. 5.

\section{Normal (11-day) gestation}

After ovulation (time 0; Fig. 5A), body weight, expressed as the per cent change from weight at time 0 , increased significantly to day 2 (Fig. $5 \mathrm{~A} ; P<0.001$ ) before plateauing on days 3,4 and 5 . Body weight increased again from day 6 , peaking on day 9 at $9.5 \%( \pm 6.7)$. A significant decline in weight on days 10 and 11 indicated the end of the gestation phase.

There were also significant differences in the body weight profile between pregnant and non-pregnant cycles during an 11-day gestation. The increase in body weight from the time of ovulation was significantly higher in non-pregnant cycles $(n=31)$ than in pregnant cycles $(n=20 ;$ Fig. 5 B $)$ on days $1(P=0.002)$ and 2 $(P=0.042)$ and the change in body weight from days 4 to 5 was significantly higher in non-pregnant cycles (Fig. 5B; $P=0.033$ ), with pregnant cycles losing weight from days 4 to 5 .

\section{Shortened (9-day) gestation}

The short gestation, resulting in a reduced luteal length, was found only in pregnant animals. Body weight change (\% change from ovulation weight; Fig. 5A) showed increased amplitude compared with a normal luteal phase, peaking at $14.9( \pm 7.3) \%$ above ovulation weight on day 7 . The developmental stage of conceptuses recovered from animals that had a continued body weight increase from days 2 to 3 , was 1 day more rapid than that expected on day $3(n=4)$. Then, in animals that also had a sharp increase in body weight on day 6 , the developmental stage was 2 days more advanced than that expected on day 7 ( $n=8$; Fig. 5A). Some animals showed only one period of rapid weight gain and conceptus development $(n=6)$, which resulted in the 10-day gestation length.

\section{Uterine mitoses}

Mitotic activity was found in the uterine epithelium during the follicular and luteal phase, between days -7 and 4 (Fig. 6A), with a further incidence of mitosis on day 8 in pregnant or day 9 in non-pregnant cycles (Fig. 6B-D). Mitotic activity was clearly visible in the cytoplasm of the cells of the epithelium (Fig. 6E and F).

On day 3, the day of unilaminar blastocyst formation, mitotic activity in the apical glandular epithelium 
of pregnant cycles was significantly higher than that in non-pregnant cycles (Fig. 6C, E and F; $P=0.037$ ).

A previously unidentified final pulse of mitotic activity was observed in pregnant animals in the basal glandular and luminal epithelium on day 8 (Fig. 6B and D), the day prior to implantation, and in non-pregnant animals in the apical glandular epithelium on day 9 (Fig. 6C).

The pattern of mitotic activity in non-pregnant cycles (Fig. 6A) suggests that there were three waves of mitotic activity in the luminal and glandular epithelium (Fig. 6A) during the follicular phase, beginning on day -7 , the beginning of the follicular phase; day -4 , the beginning of oestrus and day -1 , the end of oestrus. The beginning of each wave was defined as where the mitotic index in the basal glandular epithelium was higher than in the apical or luminal epithelium (days -7 and -4 ) or was the only epithelium with a positive mitotic index $($ day -1$)$. Day 2 was not considered the beginning of a fourth wave as the mitotic index on the surrounding days suggested that it was the peak of the third wave.

\section{Discussion}

For the first time in a polyovular marsupial, conceptus number was correlated with increased ovarian progesterone concentration (Fig. 3), suggesting that there is a conceptus effect on progesterone concentration just prior to implantation (day 8). Previous studies in dasyurids (Hinds 1989, Hinds \& Selwood 1990) have found that plasma progesterone concentrations are (non-significantly) higher in pregnant animals during unilaminar blastocyst expansion; however, the large and variable numbers of oocytes ovulated and conceptuses formed in dasyurids makes a direct comparison between pregnant and non-pregnant animals limited and difficult, unless the conceptuses are grouped in size classes as done here.

The relationship between plasma progesterone concentration and conceptus development identified in A. agilis (Hinds \& Selwood 1990) was also found here in S. macroura. Furthermore, periods of rapid conceptus development and high plasma progesterone concentration corresponded with periods of increasing body weight in $S$. macroura. Using the correlation between daily body weight change and plasma progesterone concentration, modifications in the timing of conceptus development, which allow the compression of pregnancy to produce a 9-day gestation length, can be predicted. A precise 11-day timetable of development for S. macroura (Selwood \& Hickford 1999) shows a fourcell arrest on days 1.5-2.5, which corresponds with the plateau in body weight found in this study from days 2 to 3. The period of slow unilaminar blastocyst expansion corresponds with the slow increase in body weight found from days 3 to 7 , and formation of the bilaminar blastocyst was indicated by an increase in body weight on day 7 . In the shortened gestation, however, body weight increased from days 2 to 3 , suggesting that the four-cell arrest was reduced or lost, and the rapid increase in body weight found on day 6 indicates that bilaminar blastocyst formation occurred earlier, and thus definitive blastocyst expansion was quicker than that in the normal gestation. The shortened gestation identified here suggests that the conceptus itself may provide the stimulus to speed up gestation. A conceptus influence on gestation length has previously been identified in macropodids (Merchant 1976, 1979, Merchant \& Calaby 1981), but this is the first time a conceptus influence on gestation length has been identified in a dasyurid.

These data also suggest that pregnant luteal phases with a normal gestation length can be identified from a reduction in body weight from days 4 to 5 (Fig. 5B). The loss of body weight from days 4 to 5 (Fig. 5B) in normal length pregnant cycles was not anticipated, but may indicate that extra maternal energy is required during primary expansion of the blastocyst. Furthermore sharp increases in weight on days 2 or 6 indicate that gestation is being shortened (Fig. 5A), which this study showed is likely to be a result of conceptus influence.

The uterine epithelial mitotic activity observed during the follicular phase supports previous suggestions that after parturition, the remaining epithelial cells undergo extensive replication during the follicular phase to regenerate the epithelium (Shorey \& Hughes 1972). Recent studies have identified stem cells in the human basalis epithelium whose daughter cells undergo repeated divisions to create the new epithelium after menstruation and parturition (Gargett 2004). The basal initiation of mitosis, followed by apical and then luminal mitosis during the follicular phase, suggests that this may also occur in S. macroura. Increased mitotic activity in the glandular epithelium of pregnant $S$. macroura on day 3 (unilaminar blastocyst formation) corresponds with increased glandular density in pregnant A. agilis (Cruz \& Selwood 1993) and possibly S. macroura (Cruz \& Selwood 1997), suggesting that increased cell numbers in the glandular epithelium are required to maintain pregnancy, as glandular secretions are holocrine (Shorey \& Hughes 1973a) resulting in cell loss.

The significant increase in uterine weight observed in pregnant $S$. macroura, which was correlated with a period of increased uterine mitotic activity, supports previous suggestions that uterine weight changes are due to mitotic activity (Tyndale-Biscoe 2005) during early gestation, but later in gestation, they are more likely to be due to stromal oedema as shown by Cruz \& Selwood (1997).

Early pregnancy factor (EPF), a protein detected in maternal serum, is found in $S$. macroura within $24 \mathrm{~h}$ of fertilization and is found at high levels between zygote uterine entry and unilaminar blastocyst formation (days $1-3)$, as well as immediately pre-implantation on day 8 (Cruz et al. 2001). EPF is found in mice during these developmental stages, where it is required for zygote survival and cleavage, and it is also found during the peri-implantation period (Athanasas-Platsis et al. 2000). EPF is associated with mitotic activity in the ovary of $S$. 
macroura (Cruz et al. 2001) as in mice (Athanasas-Platsis et al. 2000). Here, increased mitotic activity in the pregnant uterine epithelium of $S$. macroura, was coincident with the previously identified periods of elevated serum EPF (Cruz et al. 2001), suggesting a possible relationship between EPF and uterine epithelial mitotic activity in $S$. macroura.

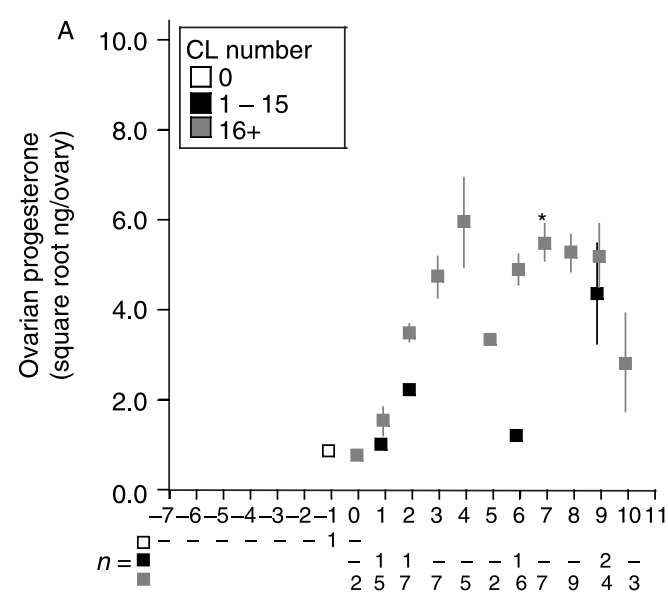

Day of follicular and luteal phase
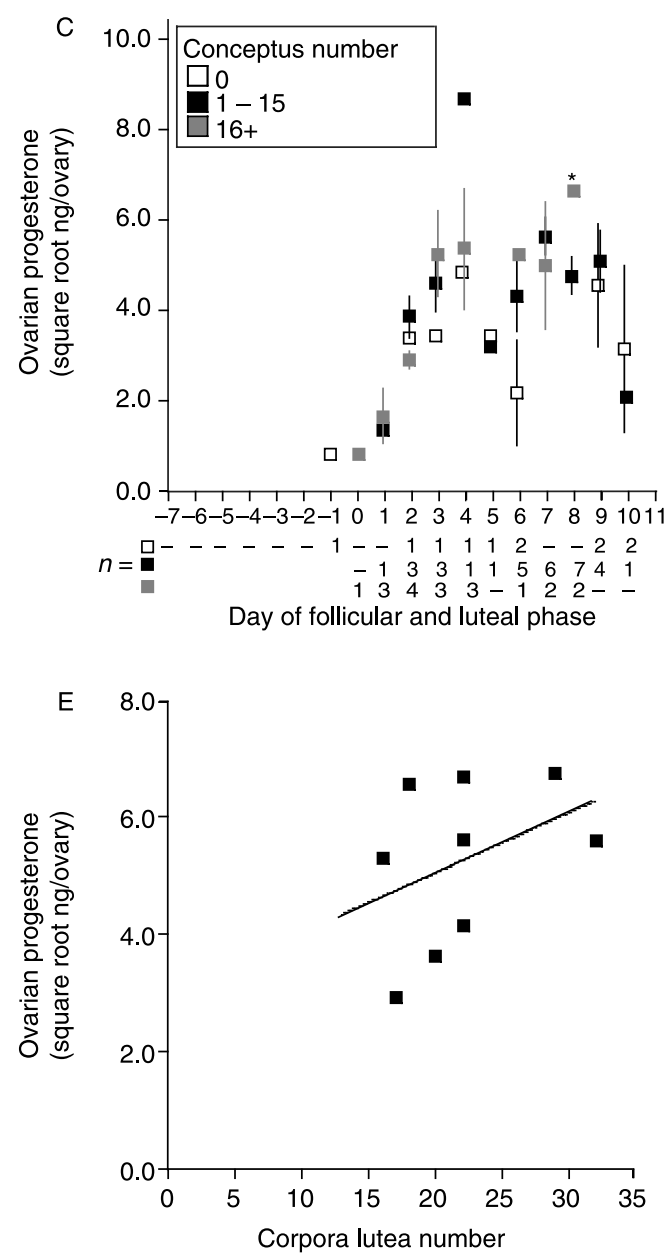

The final epithelial mitotic pulse observed during implantation has not previously been identified in a marsupial. Mitosis in the luminal and glandular epithelium is observed just prior to implantation in mice (Finn \& Martin 1967), ferrets (Gulamhusein \& Beck 1973) and horses (Gerstenberg et al. 1999). In vitro, this mitosis is stimulated by oestrogen (Martin \& Finn 1968), and the mitosis just

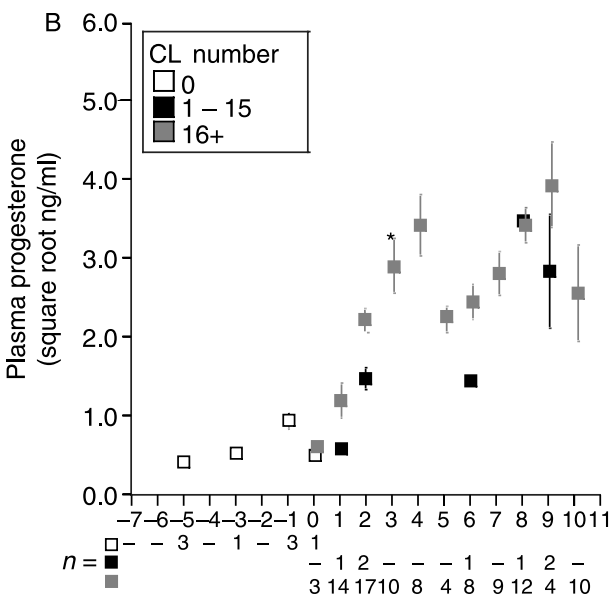

Day of follicular and luteal phase

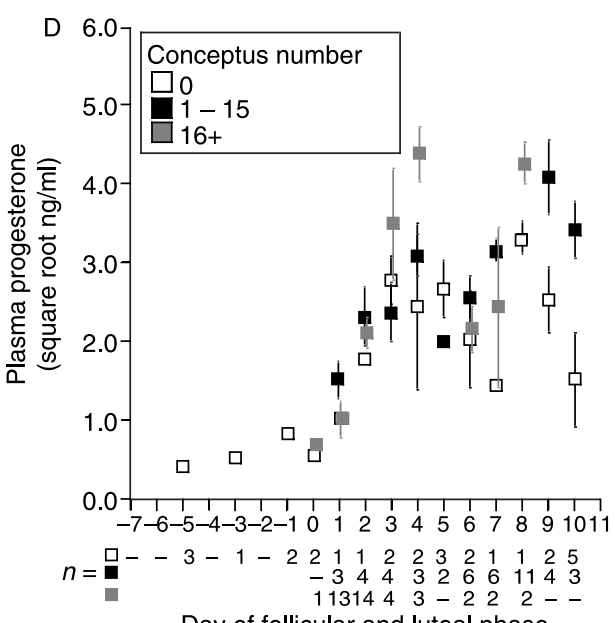

Day of follicular and luteal phase

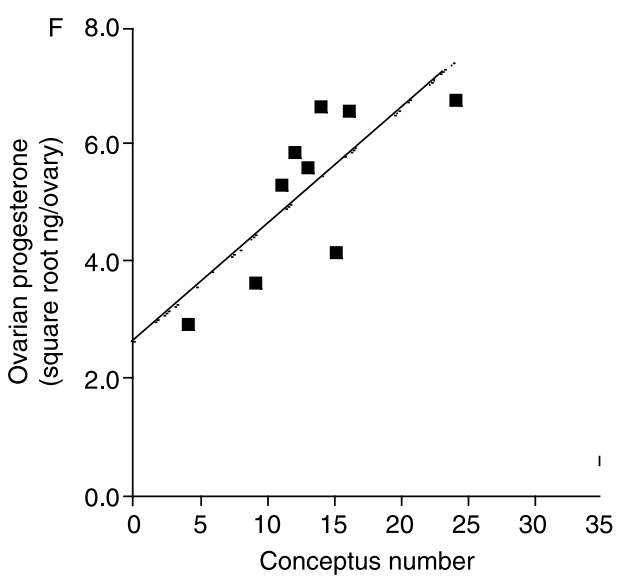


prior to implantation is presumed to be a delayed response to the pre-ovular oestrogen in mice (Tranguch et al. 2005), but is thought to be a response to conceptus-secreted oestrogen in horses (Gerstenberg et al. 1999). The final mitotic pulse observed here occurred in both pregnant and non-pregnant cycles. It is possible that the pregnant mitotic pulse might be a response to conceptus-secreted oestrogen; however, the pulse observed in non-pregnant animals suggests that the oestrogen stimulus may be ovarian in origin, and that the presence of conceptus in pregnant animals acted to advance the mitotic pulse by one day. In pregnant $S$. macroura, which have invasive placentation (Selwood \& Woolley 1991), a mitotic pulse just prior to implantation may be required to assist implantation. The final mitotic pulse in non-pregnant uteri may be associated with the shedding of the glandular epithelium, seen in nonpregnant S. macroura on days 9 and 10 of the gestation phase (data not shown).

For the first time in a polyovular marsupial, this study clearly demonstrates conceptus-driven modifications to the pregnant luteal phase.

\section{Materials and Methods}

\section{Animals}

A colony of $S$. macroura maintained by LS at La Trobe University and The University of Melbourne between 1985 and 2005 provided the 360 experimental animals used as follows: ovarian progesterone, 66; plasma progesterone, 117; uterine weight, 117; epithelial mitotic index, 80; daily body weight, 109 and development during shortened gestation, 18. All animals included in this study were used principally for other studies, and of these 360 animals, 275 animals provided one sample used in this paper, 32 provided two, 42 provided three and 11 provided four samples. This study followed the Australian National Health and Medical Research Council guidelines for the Care and Use of Animals for Scientific Purposes.

\section{Monitoring of the oestrous cycle for staged sample collection (blood, ovary, uterine weight and animal weight)}

Daily monitoring (July-December) of animal weight and morning urine samples identified the stage of the oestrous cycle as described previously (Selwood \& Woolley 1991). The time that the ovulation sample is taken is defined as time 0 , and the timing of the luteal phase is calculated from this time (Selwood \& Hickford 1999).

\section{Blood and tissue collection}

Females were killed by halothane (Rhone Merieux, West Footscray, VIC, Australia) inhalation followed by cervical dislocation while anaesthetized. Blood was collected from the posterior vena cava using a $21 \mathrm{G}$ needle and $3 \mathrm{ml}$ syringe. The reproductive tract was washed and stored in sterile warmed $\left(35^{\circ} \mathrm{C}\right)$ calcium- and magnesium-free PBS. The number of follicles/CL on the ovaries and eggs/conceptuses in the oviducts/uteri were counted and each uterus weighed with all conceptuses removed if pregnant, but not from day 9 or 10 of gestation as implantation had occurred and the conceptuses could not be separated from the uterine endometrium. The developmental stage of the follicles/CL and oocytes/conceptuses confirmed the day of the cycle predicted from reproductive monitoring. Assessment of uterine conceptuses used the criteria in Selwood \& McCallum (1987). Unless indicated, all samples were collected from a normal (11-day) gestation.

\section{Progesterone assay}

All progesterone assays were conducted within 6 months of collection on tissue and blood collected between 1985 and 1991. Plasma and ovarian progesterone concentrations were determined using the RIA procedure originally described for the tammar wallaby (M. eugenii) by Sernia et al. (1980). The sensitivity of the assay was $25 \mathrm{pg} / \mathrm{ml}$ or $0.2 \mathrm{ng} / \mathrm{ml}(0.64 \mathrm{nmol} / \mathrm{l})$ plasma. The hexane solvent blank and the charcoal-treated ('steroid-free') plasma always gave readings below the sensitivity of the assay. Addition of a range of concentrations of cold progesterone to normal and charcoal-treated plasma gave recoveries within $7 \%$ of expected $(n=10)$. Serial dilutions of plasma were parallel with the inhibition curves obtained with standards prepared in buffer. Intra- and inter-assay coefficients of variation were $9 \%(n=10)$ and $15 \%(n=12)$ respectively.

The square root of the assay results was used in statistical analysis to normalize these data. Plasma progesterone concentration is given as $\mathrm{ng} / \mathrm{ml}$, but ovarian progesterone is given as ng/ovary to account for luteal cell hypertrophy, and to express the production rate for each ovary.

Figure 3 Variation in ovarian and plasma progesterone concentration in S. macroura related to corpora lutea $(\mathrm{CL})$ and conceptus number. The number of $C L$ and conceptuses is divided into three groups to reflect none (0), average (1-15) and large (16+) numbers. (A) Ovarian progesterone concentration was significantly correlated with $\mathrm{CL}$ number during the entire luteal phase (controlling for the day of the luteal phase and conceptus number; $r=0.3754, n=56, P=0.004)$, with the strongest correlation found between days 3 and $7(r=0.5892, n=25, P<0.001)$. A significant daily correlation was found on day 7 (controlling for conceptus number; $r=0.7550, n=5, P=0.050$ ), but not day $8(r=-0.0645, n=6, P=0.879)$. (B) Plasma progesterone concentration was significantly correlated with CL number during the entire luteal phase (controlling for day of gestation and conceptus number: $r=0.2499, n=80, P=0.015)$, with the strongest correlation found between days 3 and $9(r=0.3341, n=53, P=0.013)$. A significant daily correlation was found on day 3 (controlling for conceptus number; $r=0.7546, n=6, P=0.030$ ), but not day 4 ( $r=0.0347, n=5$, $P=0.941$ ). (C) Ovarian progesterone concentration was significantly correlated with conceptus number on day 8 (controlling for $C L$ number; $r=0.7118, n=6, P=0.048$ ). (D) Plasma progesterone concentration was strongly correlated with conceptus number throughout the luteal phase; however, this was non-significant when $C L$ number was controlled ( $r=-0.1426, \mathrm{df}=78, P=0.207$ ). (E) Regression analysis of ovarian progesterone concentration and CL number on day 8 of the luteal phase. (F) Regression analysis of ovarian progesterone concentration and conceptus number on day 8 of the luteal phase. ${ }^{*}$ Significant correlation. 


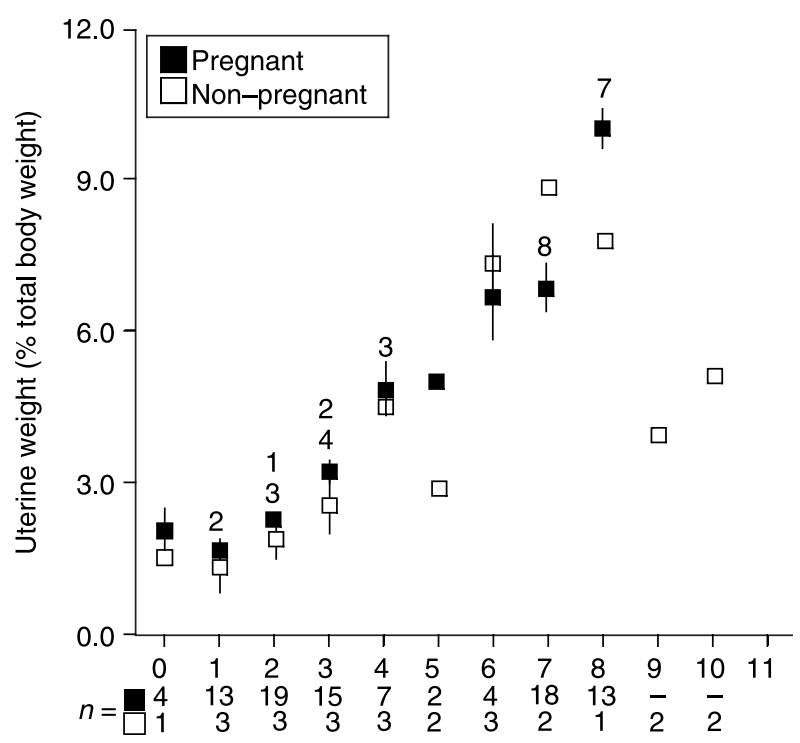

Day of luteal phase

Figure 4 S. macroura uterine weight (\% of total body weight) during the luteal phase in pregnant and non-pregnant oestrous cycles. Uterine weight increased significantly between days 1 and 2, 2 and 3, 3 and 4, and 7 and $8\left(F_{9,95}=61.953, P<0.001\right)$ in pregnant cycles. No pregnant samples were collected on day 9 or 10 as implanted conceptuses cannot be separated from the uterine endometrium. The number above the data point indicates a significant difference between that day and the data point. Sample sizes ( $n$ ) are given below each day.

\section{Uterine epithelial mitotic index}

Uteri collected during the follicular and luteal phases of the oestrous cycle were flattened on filter paper and fixed overnight in $4 \% \mathrm{w} / \mathrm{v}$ paraformaldehyde (Merck-BDH) in PBS, before being dehydrated in $70 \%$ ethanol and embedded in paraffin wax, sectioned at $6 \mu \mathrm{m}$ and stained with haematoxylin-eosin. Under light microscopy $(400 \times)$, mitotic divisions in epithelial cells were clearly visible. A cell was scored as mitotic only if chromosomes were clearly visible, which excluded the prophase from the counts. The mitotic index, defined as the percentage of cells undergoing mitosis (Freshney 1994), was calculated for each day of the follicular and luteal phase in the three uterine epithelial regions, the luminal, apical glandular and basal glandular (Shorey \& Hughes 1973a), using a protocol modified from Freshney (1994). Individual glands or sections of luminal epithelium in the middle third of the microscopic view were randomly sampled until at least 150 cells were counted for each region, which was usually nine glands per animal or one-third microscopic view of luminal epithelium and the proportion of mitotic cells calculated. Arc sin transformation was used to normalize these data before conversion to a percentage.

\section{Statistical analysis}

Data were analysed using the SPSS graduate package (SPSS Inc.).

Power testing showed that a minimum of three animals (pregnant and non-pregnant) would be required for a statistically valid comparison of progesterone concentration

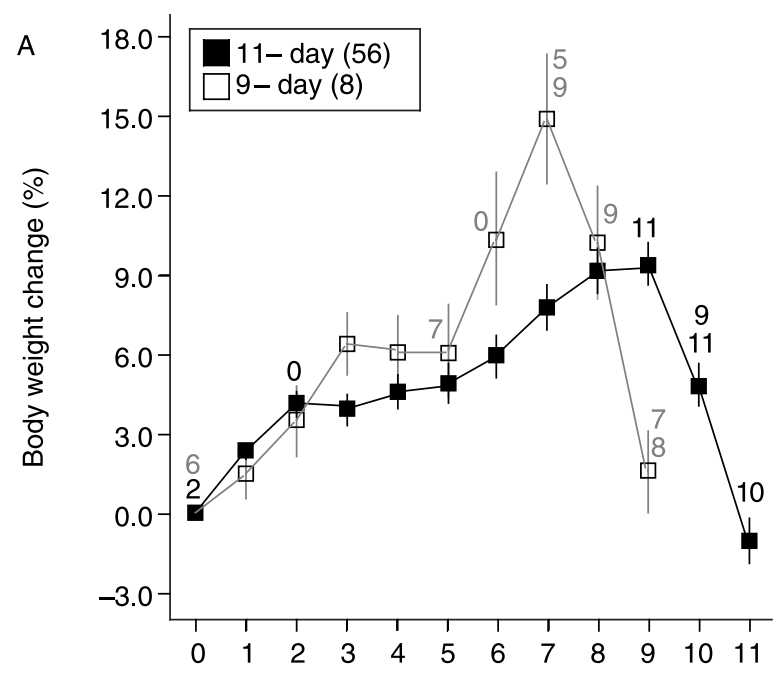

Day of luteal phase

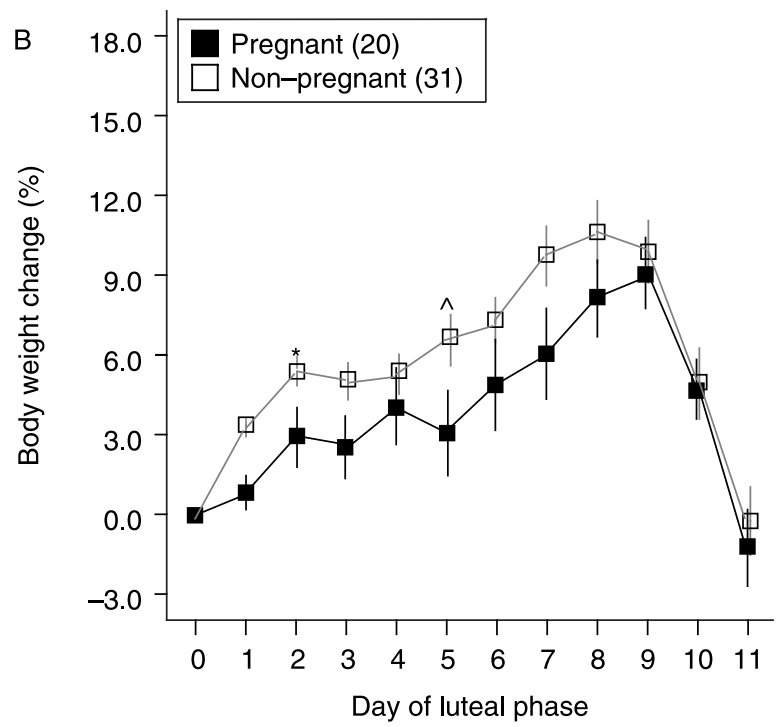

Figure 5 (A) Daily body weight change (\% change from ovulation weight) for a normal (11-day; black) and shortened (9-day; white) gestation in S. macroura. Compared with a normal gestation, animals undergoing a shortened gestation had an increased amplitude of body weight change, and continued to increase in weight on day 3 , resulting in a shortened body weight plateau during blastocyst expansion (shortened plateau: days 4-5; normal plateau: days 3-5), before a sharp increase in weight on day 6 . Body weight increased significantly from ovulation weight in the normal $\left(F_{11}\right.$, $\left.{ }_{643}=17.028, P<0.001\right)$ and shortened gestation $\left(F_{9,68}=6.973, P<0.001\right)$. The number above the data point indicates a significant change from that day. (B) Daily body weight change (\% change from ovulation weight) for a normal (11-day) gestation in pregnant (black) and non-pregnant (white) cycles. The change in body weight from ovulation weight was significantly ${ }^{*}$ ) higher in non-pregnant cycles on days $1(t=3.328, n=49, P=0.002)$ and $2(t=2.088, n=49, P=0.042)$ than in pregnant cycles. Pregnant cycles lost weight on day 5 compared with non-pregnant $(\wedge, t=2.205, n=45$, $P=0.033$ ). Sample size is given in parentheses in the key.

between pregnant and non-pregnant data on each day of the luteal phase. However, the large and variable number of oocytes ovulated by dasyurids (Tyndale-Biscoe \& Renfree 1987), including S. macroura, (Selwood \& Woolley 1991) 

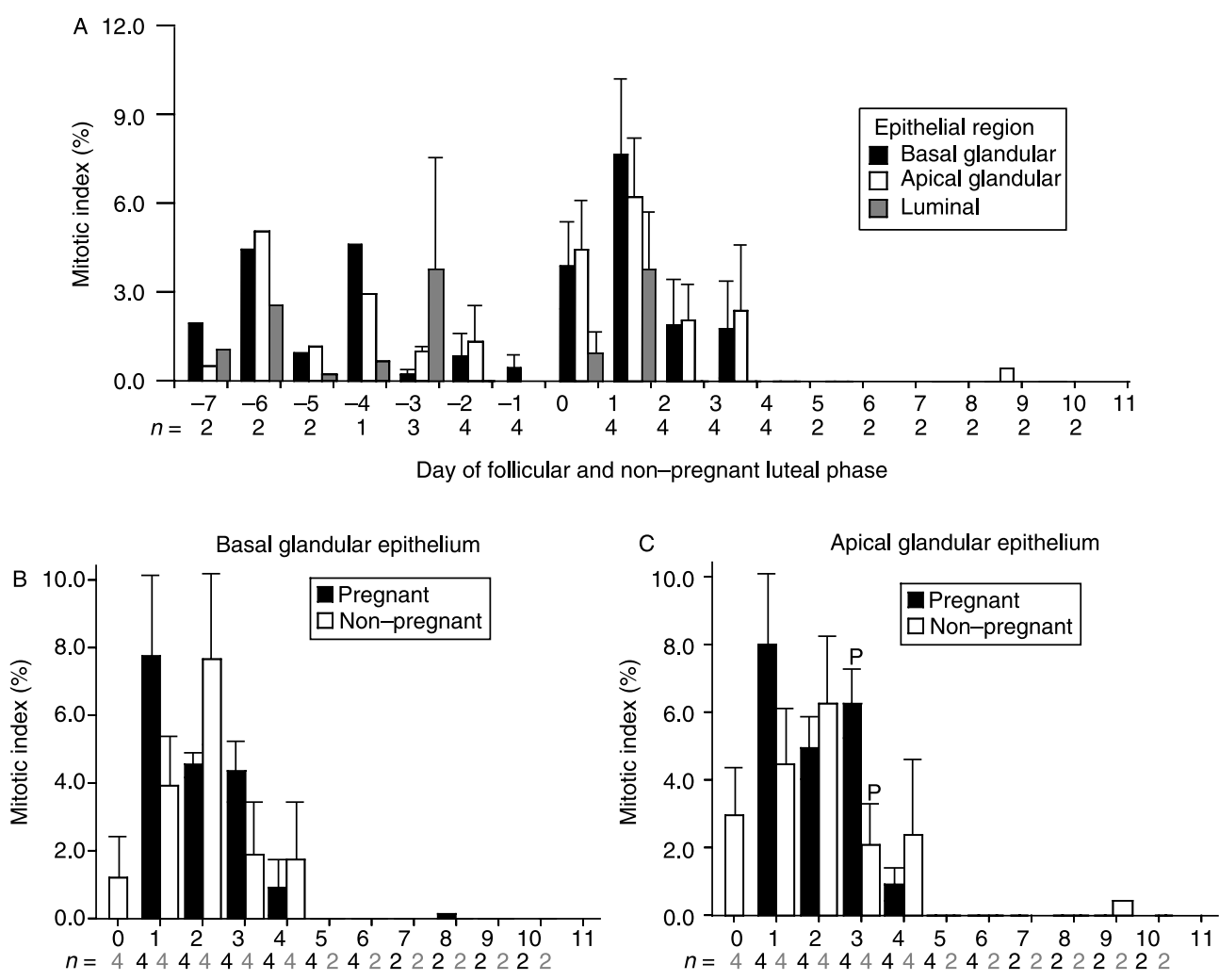

Day of luteal phase

Day of luteal phase
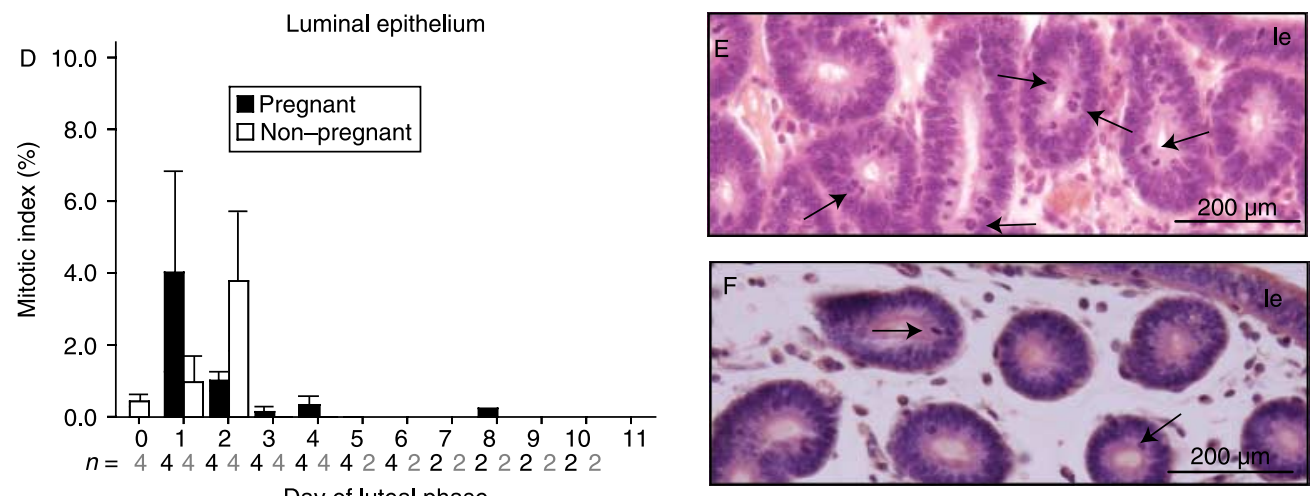

Figure 6 Daily mitotic index (\%) of uterine epithelial cells (basal glandular, apical glandular and luminal) during the follicular and luteal phase in S. macroura. (A) Follicular and non-pregnant luteal phase. Mitotic activity began on day -7 (initiation of the follicular phase) and continued until day 4 (the day of primary unilaminar blastocyst expansion), with a final pulse found only in the apical glandular epithelium on day 9 (the day of implantation). Mitotic activity fell to be significantly lower than days 1 and 2 during the late luteal phase in the glandular epithelium (basal glandular $F_{17,57}=3.800, P<0.001$; apical glandular $F_{17,57}=3.595, P<0.001$; luminal $F_{17,57}=1.61, P=0.377$ ). (B) Basal glandular epithelium during the pregnant and non-pregnant luteal phase. A final pulse of mitotic activity occurred only in pregnant animals on day 8 (trilaminar blastocyst) just before implantation. (C) Apical glandular epithelium during the pregnant and non-pregnant luteal phase. Mitotic activity was significantly higher in pregnant than in non-pregnant animals on day 3 (unilaminar blastocyst formation; $t=2.665, \mathrm{df}=6, P=0.037$ ). A final pulse of mitotic activity was observed only in non-pregnant animals on day 9. (D) Luminal epithelium during the pregnant and non-pregnant luteal phase. A final pulse of mitotic activity was found only in pregnant animals on day 8. (E and F) Apical region of the uterine glandular epithelium in S. macroura on day 3 of the luteal phase. (E) Mitotic activity (arrows) in the pregnant glandular epithelium. (F) Mitotic activity in the non-pregnant epithelium. Sample sizes ( $n$ ) are given below each day in (A)-(D); (E and F) are stained with haematoxylin and eosin. le, luminal epithelium; P indicates a significant difference between pregnant and non-pregnant animals.

makes a direct comparison of progesterone concentration between pregnant and non-pregnant animals limited, as the number of CL-secreting progesterone and, presumably, total progesterone concentration will vary quite significantly between animals regardless of whether they are pregnant or not. Therefore, we examined the effect that CL or conceptus number had on progesterone concentration throughout the luteal phase using partial correlations. Pearson and partial 
correlations were also utilized to identify significant trends at the $95 \%$ confidence interval between progesterone concentration, uterine weight and animal body weight.

ANOVA was performed using the general linear models procedure with Tukey's post hoc test indicating significant differences at the $95 \%$ confidence interval in progesterone concentration, mitotic activity, uterine weight and animal body weight between each day of the luteal phase.

Individual sample $t$-tests identified significant differences in daily body weight changes between pregnant and nonpregnant cycles on each day of the follicular and luteal phase at the $95 \%$ confidence interval.

\section{Declaration of interest}

The authors declare that there is no conflict of interest that would prejudice the impartiality of this scientific work.

\section{Funding}

The research was supported by the Australian Research Council, LaTrobe University and CSIRO.

\section{Acknowledgements}

The authors would like to thank all members of the Selwood Laboratory from 1985 to 2006, particularly Lisa Masini and Kamani Nanayakkara, for the collection of data and tissue sample. Permits were obtained from Natural Resources and Environment Victoria.

\section{References}

Athanasas-Platsis S, Corcoran CM, Kaye PL, Cavanagh AC \& Morton H 2000 Early pregnancy factor is required at two important stages of development in the mouse. American Journal of Reproductive Immunology 43 223-233.

Von der Borch S 1963 Unilateral hormone effect in the marsupial Trichosurus vulpecula. Journal of Reproduction and Fertility 5 447-449.

Cake MH, Owen FJ \& Bradshaw SD 1980 Difference in concentration of progesterone in plasma between pregnant and non-pregnant quokkas (Setonix brachyurus). Journal of Endocrinology 84 153-158.

Cruz YP \& Selwood L 1993 Uterine histology of the dasyurid marsupial, Antechinus stuartii: relationship with differentiation of the embryo. Journal of Reproduction and Fertility 99 237-242.

Cruz YP \& Selwood L 1997 Histological differences between gravid and non-gravid uteri in the dasyurid marsupial, Sminthopsis macroura (Spencer). Journal of Reproduction and Fertility 111 319-325.

Cruz YP, Selwood L, Morton H \& Cavanagh AC 2001 Significance of serum early pregnancy factor concentrations during pregnancy and embryonic development in Sminthopsis macroura (Spencer) (Marsupialia: Dasyuridae). Reproduction 121 933-939.

Curlewis JD \& Stone GM 1986 Effects of oestradiol, the oestrous cycle and pregnancy on weight, metabolism and cytosol receptors in the uterus of the brush-tail possum (Trichosurus vulpecula). Journal of Endocrinology 108 201-210.

Curlewis JD, Axelson M \& Stone GM 1985 Identification of the major steroids in ovarian and adrenal venous plasma of the brush-tail possum (Trichosurus vulpecula) and changes in the peripheral plasma levels of oestradiol and progesterone during the reproductive cycle. Journal of Endocrinology 105 53-62.
Dickman CR, Parnaby HE, Crowther MS \& King DH 1998 Antechinus agilis (Marsupialia: Dasyuridae), a new species from the $A$. stuartii complex in south-eastern Australia. Australian Journal of Zoology 46 1-26.

Finn CA \& Martin L 1967 Patterns of cell division in the mouse uterus during early pregnancy. Journal of Endocrinology 39 593-597.

Fleming MW \& Harder JD 1981 Uterine histology and reproductive cycles in pregnant and non-pregnant opossums, Didelphis virginiana. Journal of Reproduction and Fertility $6321-24$.

Fletcher TP 1989 Plasma progesterone and body weight in the pregnant and non-pregnant Kowari, Dasyuroides byrnei (Marsupialia: Dasyuridae). Reproduction, Fertility, and Development 1 65-74.

Freshney RI 1994 Culture of Animal Cells: A Manual of Basic Technique, 3 edn. New York: Wiley-Liss.

Gargett CE 2004 Stem cells in gynaecology. Australian and New Zealand Journal of Obstetrics and Gynaecology 44 380-386.

Gerstenberg C, Allen WR \& Stewart F 1999 Cell proliferation pattern during development of the equine placenta. Journal of Reproduction and Fertility 117 143-152.

Gulamhusein AP \& Beck F 1973 Light and electron microscopic observations at the pre- and early post-implantation stages in the ferret uterus. Journal of Anatomy 115 159-173.

Hartman CG 1928 The breeding season of the opossum (Didelphis virginiana) and the rate of intra-uterine and postnatal development. Journal of Morphology 46 143-215.

Hinds LA 1989 Plasma progesterone through pregnancy and the estrous cycle in the Eastern Quoll, Dasyurus viverrinus. General and Comparative Endocrinology 75 110-117.

Hinds LA \& Selwood L 1990 Plasma progesterone concentrations during pregnancy in the dasyurid marsupial, Antechinus stuartii: relationship with differentiation of the embryo. Reproduction, Fertility, and Development 2 61-70.

Hinds LA \& Tyndale-Biscoe CH 1982 Plasma progesterone levels in the pregnant and non-pregnant tammar, Macropus eugenii. Journal of Endocrinology 93 99-107.

Martin L \& Finn CA 1968 Hormonal regulation of cell division in epithelial and connective tissues of the mouse uterus. Journal of Endocrinology $\mathbf{4 1}$ 363-371.

Menkhorst EM, Ezard N \& Selwood L 2007 Induction of ovulation and natural oestrous cycling in the stripe-faced Dunnart, Sminthopsis macroura. Reproduction 133 495-502.

Merchant JC 1976 Breeding biology of the agile wallaby, Macropus agilis (Gould) (Marsupialia: Macropodidae). Australian Wildlife Research 3 93-103.

Merchant JC 1979 The effect of pregnancy on the interval between one oestrus and the next in the tammar wallaby, Macropus eugenii. Journal of Reproduction and Fertility 56 459-463.

Merchant JC \& Calaby JH 1981 Reproductive biology of the red-necked wallaby (Macropus ruefogriseus banksianus) and Bennett's wallaby (M. $r$. rufogriseus) in captivity. Journal of Zoology 194 203-217.

Renfree MB 1972 Influence of the embryo on the marsupial uterus. Nature $240475-477$.

Renfree MB 1973 Proteins in the uterine secretions of the marsupial Macropus eugenii. Developmental Biology 32 41-49.

Renfree MB \& Tyndale-Biscoe CH 1973 Intrauterine development after diapause in the marsupial Macropus eugenii. Developmental Biology 32 28-40.

Selwood L 1980 A timetable of embryonic development of a dasyurid marsupial Antechinus stuartii (Macleay). Australian Journal of Zoology 28 649-668.

Selwood L \& Hickford DE 1999 Early cell lineages in marsupial embryos. In Cell Lineage and Fate Determination, pp 505-519. Ed. S Moody. Burlington: Academic Press.

Selwood L \& McCallum F 1987 Relationship between longevity of spermatozoa after insemination and the percentage of normal embryos in brown marsupial mice (Antechinus stuartii). Journal of Reproduction and Fertility 79 495-503.

Selwood L \& Woolley PA 1991 A timetable of embryonic development, and ovarian and uterine changes during pregnancy, in the stripe-faced dunnart, Sminthopsis macroura (Marsupialia: Dasyuridae). Journal of Reproduction and Fertility $91213-227$.

Sernia C, Hinds LA \& Tyndale-Biscoe CH 1980 Progesterone metabolism during embryonic diapause in the tammar wallaby, Macropus eugenii. Journal of Reproduction and Fertility 760 139-147. 
Shorey CD \& Hughes RL 1972 Uterine glandular regeneration during the follicular phase in the marsupial Trichosurus vulpecula. Australian Journal of Zoology 20 235-247.

Shorey CD \& Hughes RL 1973 a Cyclical changes in the uterine endometrium and peripheral plasma concentrations of progesterone in the marsupial Trichosurus vulpecula. Australian Journal of Zoology 21 1-19.

Shorey CD \& Hughes RL $1973 b$ Development, function, and regression of the corpus luteum in the marsupial Trichosurus vulpecula. Australian Journal of Zoology 21 477-489.

Tranguch S, Daikoku T, Guo Y, Wang H \& Dey SK 2005 Molecular complexity in establishing uterine receptivity and implantation. Cellular and Molecular Life Sciences 62 1964-1973.

Tyndale-Biscoe CH 2005 Life of Marsupials, 2 edn. Collingwood, VIC, Australia: CSIRO Publishing.

Tyndale-Biscoe CH \& Renfree MB 1987 Reproductive Physiology of Marsupials, Cambridge: Cambridge University Press.
Tyndale-Biscoe CH, Hinds LA, Horn CA \& Jenkin G 1983 Hormonal changes at oestrus, parturition and post-partum oestrus in the tammar wallaby (Macropus eugenii). Journal of Endocrinology 96 155-161.

Woolley PA 1966 Reproduction in Antechinus spp. and other dasyurid marsupials. Symposium of the Zoological Society of London 15 281-294.

Woolley PA 1990 Reproduction in Sminthopsis macroura (Marsupialia: Dasyuridae) 1. The Female. Australian Journal of Zoology 38 187-205.

Received 17 January 2008

First decision 26 February 2008

Revised manuscript received 18 September 2008

Accepted 20 October 2008 